\title{
Spectrophotometric determination of Naproxen as ion-pair with bromophenol blue in bulk, pharmaceutical preparation and human serum samples
}

\author{
Fereshteh Keyhanian, Nina Alizadeh* and Abdollah Fallah Shojaie
}

\begin{tabular}{|c|c|}
\hline$\overline{C H R O N I C L E}$ & ABSTRACT \\
\hline $\begin{array}{l}\text { Article history: } \\
\text { Received March } 27,2013 \\
\text { Received in Revised form } \\
\text { August } 27,2013 \\
\text { Accepted } 19 \text { October } 2013 \\
\text { Available online } \\
31 \text { October } 2013\end{array}$ & $\begin{array}{l}\text { A highly sensitive, accurate and simple spectrophotometric method was established for } \\
\text { determination of naproxen (NAP). The method involved ion-pair complex formation between } \\
\text { naproxen and bromophenol blue (BPB). The colored product was measured at } 432 \mathrm{~nm} \text {. The } \\
\text { reaction conditions were optimized. The absorbance was found to increase linearly with } \\
\text { increase in concentration of NAP which was corroborated by correlation coefficient value. } \\
\text { Beer's law was obeyed in the concentration range of } 1-110 \mu \mathrm{gL}^{-1} \text { with molar absorptivity of }\end{array}$ \\
\hline $\begin{array}{l}\text { Keywords: } \\
\text { Naproxen } \\
\text { Spectrophotometry } \\
\text { Ion-pair complex } \\
\text { Bromophenol blue } \\
\text { Pharmaceutical formulation }\end{array}$ & $\begin{array}{l}\text { method are } 0.292 \text { and } 0.973 \mu \mathrm{g} \mathrm{mL}^{-1} \text {, respectively. Recovery of the method was carried out by } \\
\text { standard addition method. Recovery studies and statistical data proved the accuracy, } \\
\text { reproducibility and the precision of the proposed method. The common excipients did not } \\
\text { interfere in this analysis. Hence the method is useful for routine estimation of naproxen in } \\
\text { pharmaceutical formulation and human serum samples. }\end{array}$ \\
\hline
\end{tabular}

\section{Introduction}

Naproxen (NAP) [(+)-2-(6-methoxy-2-naphthyl) propionic acid, is a non-steroidal antiinflammatory drug (NSAID). Naproxen exhibits analgesic and antipyretic properties (Scheme 1).Naproxen used for treatment of fever, inflammation, rheumatoid arthritis, primary dysmenorrheal and gout. Anti-inflammatory effects of naproxen are generally thought to be related to its inhibition of cyclooxygenase and consequent decrease in prostaglandin concentrations in various fluids and tissues ${ }^{1,2}$. Like other NSAIDs, naproxen is capable of producing disturbances in the gastrointestinal tract; it is also associated with the smallest overall cardiovascular risks ${ }^{3}$. Naproxen is rapidly and completely absorbed after oral administration, and it is the predominant species in serum, with a therapeutic range of 30 to $90 \mu \mathrm{g} \mathrm{mL}^{-14}$.

Naproxen has been determined by several analytical methods like: HPLC ${ }^{5-7}$, HPTLC ${ }^{8}$, LC-MS/MS ${ }^{9,10}$, capillary electrophoresis ${ }^{11,12}$, fluorimetric methods ${ }^{13}$, chemiluminescence ${ }^{14-16}$, voltammetry ${ }_{20-22}^{17,18}$, solid-phase microextraction coupled with liquid chromatography ${ }^{19}$ and spectrophotometry ${ }^{20-22}$. Although the HPLC methods are highly sensitive and specific, but they are most expensive.

\footnotetext{
* Corresponding author.

E-mail addresses: n-alizadeh@guilan.ac.ir (N. Alizadeh) 
Spectrophotometry is considered as the most convenient analytical technique in pharmaceutical analysis, because of its inherent simplicity and availability in most quality control and clinical laboratories ${ }^{23-26}$. The aim of the present work is to develop a spectrophotometric method that can be used in laboratories where modern and expensive apparatus such as GLC and HPLC are not available. The method introduced in this paper is very simple, rapid, accurate, precise, sensitive and less time consuming for quantitative determination of naproxen in pure, pharmaceutical preparation and human serum samples.

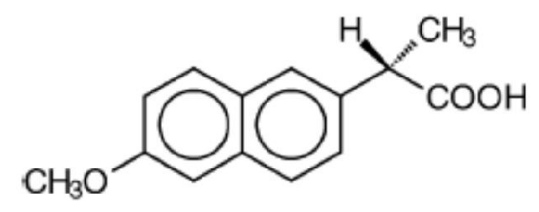

\section{Experimental}

Scheme 1, Chemical structure of naproxen.

\subsection{Apparatus}

All absorbance measurements and spectral runs were made on a RAY LEIGH UV-1800 single beam spectrophotometer with $1 \mathrm{~cm}$ matched quartz cells was used. The $\mathrm{pH}$ measurements were carried out with a Metrohm $827 \mathrm{pH}$ lab $\mathrm{pH}$ meter.

\subsection{Reagents}

All the chemicals and reagents used were of analytical grade (Merck) and used without further purification. Naproxen was supplied as gift sample from Sobhan Pharmaceutical (Rasht, Iran). Tablet formulation of naproxen was obtained from a local pharmacy for analysis.

\subsection{Solutions}

\subsubsection{Stock standard solutions of naproxen}

A stock standard solution $\left(200 \mu \mathrm{g} \mathrm{mL}^{-1}\right)$ was prepared by dissolving accurately weighed $20 \mathrm{mg}$ of pure naproxen in methanol and diluting to the mark with the same solvent in a $100 \mathrm{~mL}$ calibrated flask. This stock solution was diluted appropriately with methanol to obtain suitable working solutions. Freshly prepared solutions were always employed.

\subsubsection{Stock standard solution of reagent}

Stock solution of BPB $\left(100 \mu \mathrm{g} \mathrm{mL}^{-1}\right)$, was prepared by dissolving $10 \mathrm{mg}$ of reagent in methanol and diluting to the mark with double distilled water in a $100 \mathrm{~mL}$ calibrated flask. This solution was stable for one week.

\subsection{General procedure}

\subsubsection{Procedure for preparation of calibration curve}

BPB method: Aliquots equivalent to $1-110 \mu \mathrm{g} \mathrm{mL}^{-1}$ naproxen were transferred into a series of $5 \mathrm{~mL}$ volumetric flasks. To each flask, $1 \mathrm{~mL}$ of $50 \mu \mathrm{g} \mathrm{mL}^{-1}$ of BPB solution and $1 \mathrm{~mL}$ of phosphate buffer solution $(\mathrm{pH}=3.0)$ were added and diluted to mark with methanol and distilled water, then the prepared standard solutions were left to stand for $10 \mathrm{~min}$ at room temperature $\left(22^{\circ} \mathrm{C}\right)$. The absorbance of the yellow colored complexes was measured at $432 \mathrm{~nm}$ against a blank reagent 
prepared in the same way without addition of the naproxen [Table 1]. To obtain the standard calibration graph, values of absorbance against the drug concentration was plotted (Fig.1).

Table 1. Spectra and statistical data for the spectrophotometric determination of naproxen

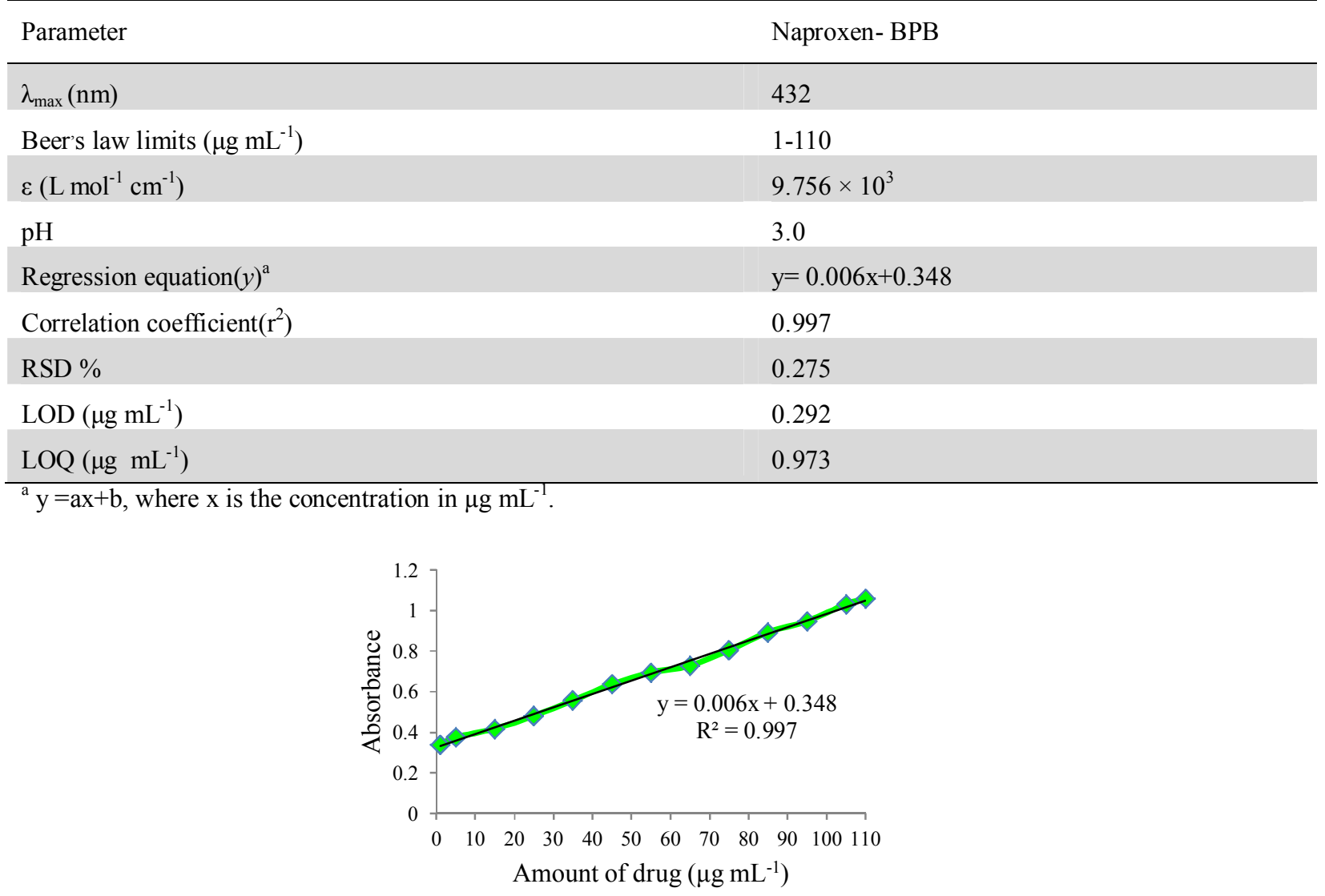

Fig. 1. Calibration curve of naproxen-BPB complex

\subsubsection{Procedure for the assay of tablets}

In analysis of naproxen in tablets by the proposed method, ten tablets of naproxen were weighed and pulverized into a fine powder. An accurately weighed portion of the powdered tablets equivalent to $250 \mathrm{mg}$ of naproxen was transferred into $100 \mathrm{~mL}$-beaker and was dissolved in the least amount of methanol, filtered through a Whatman filter paper (No. 41 ) and transferred into a $100 \mathrm{~mL}$ calibrated flask and diluted to volume with methanol. Solutions of working range concentration were prepared by proper dilution of this stock solution with methanol and followed the above procedure for the analysis. The drug content of the tablet formulation was then calculated [Table 2]. For further confirmation, the standard addition technique was applied to test the reliability and recovery of the proposed method, in which variable amounts of the drug were added to the previously analyzed portion of pharmaceutical [Table 3].

Table 2. Determination of naproxen in tablet dosage form using proposed method

\begin{tabular}{lcccc}
\hline Method & Naproxen labeled amount $(\mathrm{mg})$ & Founded $(\mathrm{mg})$ & Recovery $(\%)$ & RSD $^{\mathrm{a}}(\%)$ \\
\hline BPB & 250 & 249.36 & 99.74 & 0.53 \\
\hline
\end{tabular}

${ }^{\mathrm{a}}$ Mean of four determination 
Table 3. Application of the standard addition technique for the determination of naproxen in tablet dosage form

\begin{tabular}{|c|c|c|c|c|}
\hline \multirow{2}{*}{ Sample } & \multirow{2}{*}{ Taken $\left(\mu \mathrm{g} \mathrm{mL}^{-1}\right)$} & \multirow{2}{*}{ Added $\left(\mu \mathrm{g} \mathrm{mL}^{-1}\right)$} & \multicolumn{2}{|l|}{$\mathrm{BPB}$} \\
\hline & & & Founded $^{\mathrm{a}}\left(\mu \mathrm{g} \mathrm{mL}^{-1}\right)$ & Recovery (\%) \\
\hline $\begin{array}{l}\text { Naproxen } \\
(250 \mathrm{mg})\end{array}$ & 10 & $\begin{array}{l}0 \\
2 \\
4 \\
6\end{array}$ & $\begin{array}{c}9.87 \\
12.26 \\
14.11 \\
16.09\end{array}$ & $\begin{array}{c}98.70 \\
102.25 \\
100.78 \\
100.56\end{array}$ \\
\hline
\end{tabular}

${ }^{a}$ Mean of four determination.

\subsection{Procedure for spiked serum}

The proposed method has been successfully applied for the determination of naproxen in human blood serum samples. The results were obtained from four replicate measurements of serum samples containing naproxen and indicate that the proposed method can be used for the determination of naproxen in human blood serum samples [Table 4].

Table 4. Determination of naproxen in human blood serum by proposed method

\begin{tabular}{lcccc}
\hline Method & Added $\left(\mu \mathrm{g} \mathrm{mL}^{-1}\right)$ & Recovery $(\%)$ & RSD $(\%)$ & Er $(\%)$ \\
\hline BPB & 15 & 102.00 & 0.42 & 2.00 \\
& 25 & 99.64 & 0.37 & -0.36 \\
\hline
\end{tabular}

${ }^{a}$ Mean of four determination.

\subsection{Stoichiometric relationship}

The composition of ion-pair complex was established by applying Job's method of continuous variations; a $1 \times 10^{-4} \mathrm{M}$ standard solution of naproxen and $1 \times 10^{-4} \mathrm{M}$ solution of BPB were used. A series of solutions were prepared in which the total volume of naproxen and BPB was kept at $1.0 \mathrm{~mL}$. The reagents were mixed in various proportions and diluted to volume in a $5 \mathrm{~mL}$ calibrated flask with the appropriate solvent following the above mentioned procedure. The plot reached maximum value at a mole fraction of 0.5; which indicated that a 1:1 (drug: dye) ion-pair is formed through the electrostatic attraction between positive protonated drug and BTB anion (Fig. 2).

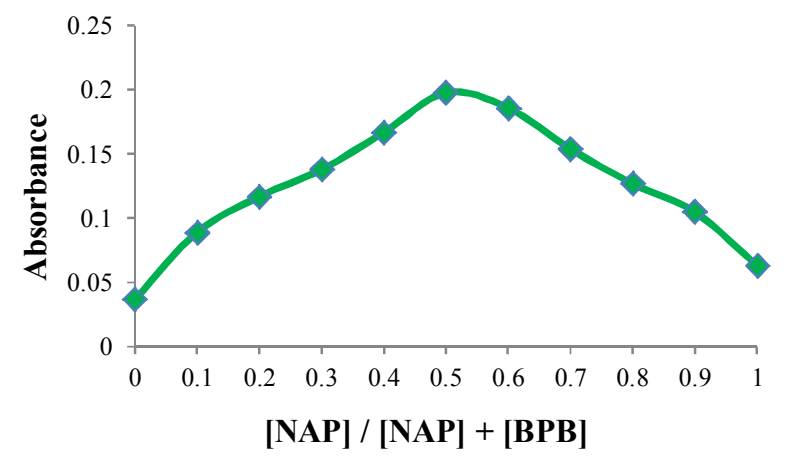

Fig. 2. Job's plot of continuous variations: reaction stoichiometry between naproxen and BPB

\section{Results and Discussion}

\subsection{Absorption spectra}


The absorption spectra of the ion-pair complex, formed between naproxen and BPB was measured at 200-800 nm against the blank solution prepared under the same conditions. Fig. 3. The complex showed maximum absorbance at $432 \mathrm{~nm}$. The measurements were made at this wavelength for tablet and human serum samples. The absorption band of the BPB showed $\lambda_{\max }$ at $572 \mathrm{~nm}$.

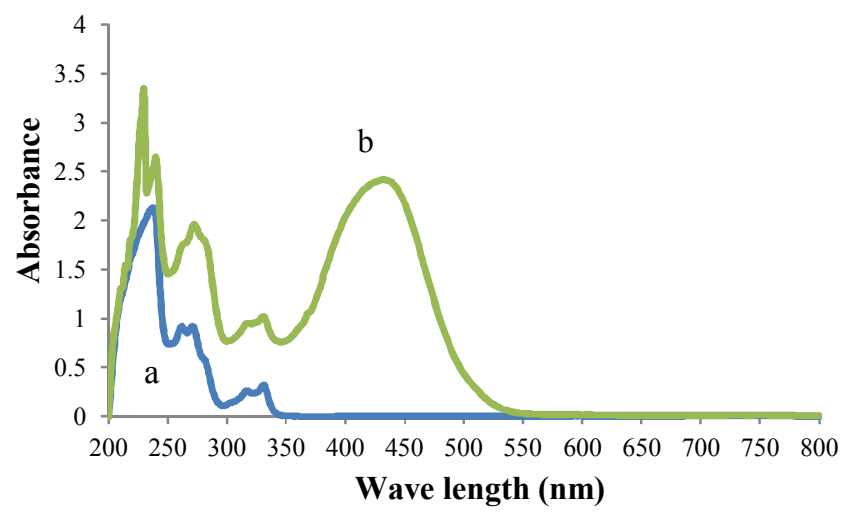

Fig. 3. Absorption spectrum of (a) pure naproxen, (b) BPB and (c) ion-pair complex of naproxen with BPB against reagent blank

\subsection{Optimum conditions for complex formation.}

In order to establish the optimum conditions necessary for a rapid and quantitative formation of the colored product with maximum stability and sensitivity, the absorbance of a series of solutions was measured by varying one parameter while keeping the others constant.

\subsubsection{Selecting of solvent}

The effect of several solvents such as ethanol, methanol, acetone, acetonitrile, dichloromethane and chloroform were investigated on the absorbance of the yellow colored complex. It was found that the reaction mixture is becoming turbid when diluted with distilled water. The difference in absorbance values with other solvents are shown in Fig. 4. It is apparent from the figure that the highest absorbance was obtained in methanol medium. Therefore, methanol was selected as the most suitable solvent.

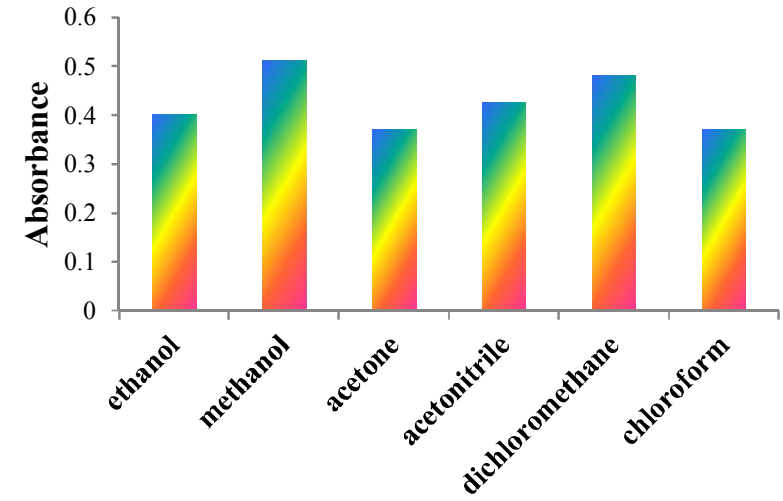

Fig. 4. Effect of different solvents on the intensity of the absorbance of naproxen-BPB complex

\subsubsection{Effect of reagent concentration}

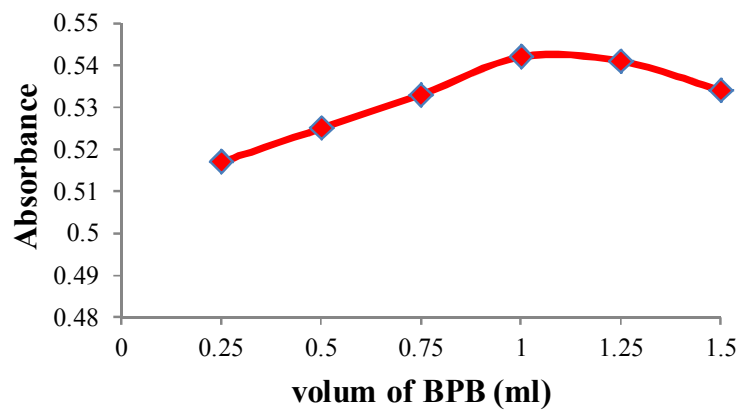

Fig. 5. Effect of dye concentration on the formation of naproxen-BPB complex 
The effect of the dye concentration on the intensity of the color developed at selected wavelength was tested using different volumes of the reagent. The results obtained showed that addition of $1 \mathrm{~mL}$ of BPB solution is the optimum volume of this reagent in the proposed procedure (Fig. 5).

\subsubsection{Effect of $p H$}

The influence of $\mathrm{pH}$ of buffer solution on the development and stability of the complex using phosphate-HCl buffer solution over the $\mathrm{pH}$ range 1.0-7.0. The maximum color intensity was observed in the $\mathrm{pH}$ of 3.0 (Fig. 6). Moreover, the optimum volume of buffer solution required to be in the proposed procedure was found to be $1 \mathrm{~mL}$.

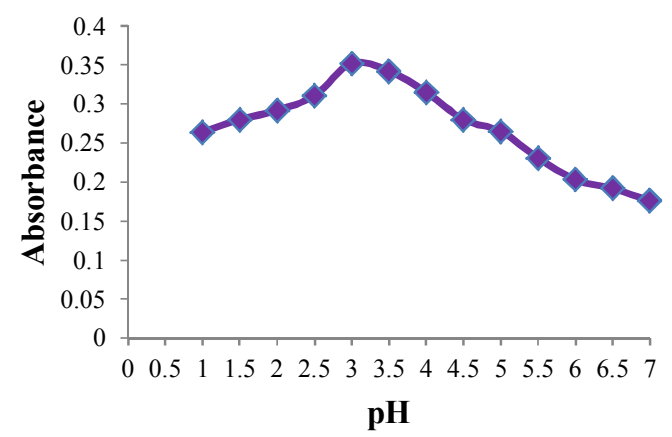

Fig. 6. Effect of $\mathrm{pH}$ on the formation of naproxen-BPB complex

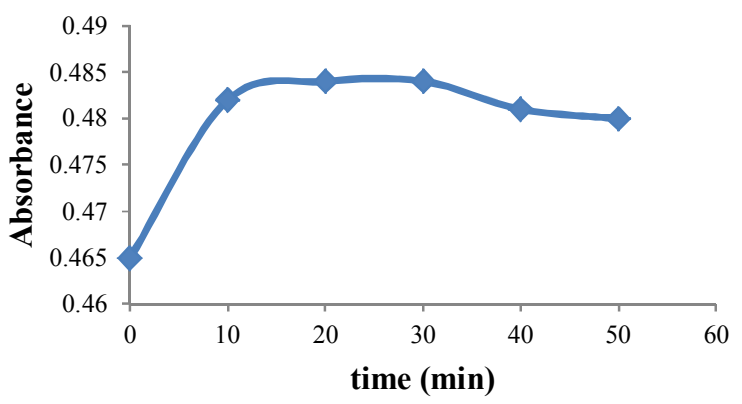

Fig. 7. Effect of time on the formation of naproxen-BPB complex

\subsubsection{Effect of reaction time}

The effect of time on the formation and stability of the ion-pair complex was studied by measuring the absorbance of the complex at different time intervals. At the beginning, the absorbance increased gradually along with the time. After $10 \mathrm{~min}$, it reached to a stable value and remained basically unaltered (Fig. 7).

\subsubsection{Effect of Sequence of additions}

The most favorable sequence is 'drug-reagent-buffer-solvent' for the complete color development and the highest absorbance at the recommended wavelength. Other sequences needed longer reaction time and produced lower absorbance values.

\subsection{Stability of ion-pair complex}

The stability of the ion-pair complex formed between drug and acidic dye was evaluated. The formation of the ion-pair complex was rapid and the yellow color product was stable for $48 \mathrm{~h}$.

\subsection{Effect of excipients}

The influence of commonly used tablet excipients (lactose, sucrose, glucose and starch) was investigated before the determination of naproxen in dosage form. No interference could be observed with the proposed method. This shows that the method is applicable in the case of pharmaceutical preparations of the naproxen.

\subsection{Method validation}

The proposed method was validated in terms of linearity, accuracy, precision, limits of detection (LOD) and quantification (LOQ). The accuracy was expressed in terms of percent recovery of the known amount of the standard drug added to the known amount of the pharmaceutical dosage forms. In order to determine the accuracy and precision of the method, solutions containing two different concentrations of the studied drug were prepared. Four replicates determinations were carried out for both pure form and the pharmaceutical preparations of naproxen. The data obtained in this 
investigation, are summarized in Table 5. The low value of RSD\% and high recovery percentage indicate good precision and reproducibility of the proposed method. The average percent recoveries obtained were quantitative, indicating good accuracy of the method.

Table 5. Test of the accuracy and precision of the proposed method for determination of naproxen

\begin{tabular}{lllll}
\hline Method & Added $\left(\mu \mathrm{g} \mathrm{mL}^{-1}\right)$ & Recovery $(\%)$ & RSD $(\%)$ & Er $(\%)$ \\
\hline BPB & 15 & 98.60 & 0.36 & -1.40 \\
& 45 & 102.47 & 0.23 & 2.57 \\
\hline
\end{tabular}

${ }^{\mathrm{a}}$ Mean of four determination.

\section{Conclusions}

The proposed method for determination of naproxen is simple, selective, sensitive, cost-effective, and free from auxiliary reagents. Moreover, the proposed method is free from tedious experimental steps such as heating and extraction. The statistical parameters and the recovery data reveal good accuracy and precision of the method. The proposed method can be used as alternative method to reported ones for the routine determination of naproxen in both pure form and in pharmaceutical formulations.

\section{Acknowledgement}

The authors express sincere thanks to Dr Mohammad Hassan Loghmani for his valuable and continuous guidance and the support of this research work by providing necessary facilities and apparatus. The authors also grateful to Sobhan Pharmaceutical (Rasht, Iran) for providing gift sample of naproxen. The authors also thankful to university of Guilan, Department of Chemistry, for providing the necessary facilities for research work.

\section{References}

1. Tripathi K.D. (2004) Essentials of Medical Pharmacology. Jaypee Brothers Medical Publishers Pvt. Ltd., New Delhi, 5, 176.

2. Rodrigues M.R., Lanzarini C.M., Ricci-Junior E. (2009) Preparation, in vitro characterization and in vivo release of naproxen loaded in poly-caprolactone nanoparticles. Pharm. Dev. Technol., 16, 12-21.

3. LodewijkEric Harrington Peter J. (1997) Twenty Years of Naproxen Technology Org. Process. Res. Dev., 1, 72-76.

4. Paulus D.F.H., Dromgoole S.H. (1987) Drugs for Rheumatic Disease. Churchill Livingstone, New York.

5. Monser L., Darghouth F. (2003) Simultaneous determination of naproxen and related compounds by HPLC using porous graphitic carbon column. J. Pharm. Biomed. Anal., 32, 1087-1092.

6. Hsu Y., Liou Y., Lee J., Chen C., Wu A. (2006) Assay of naproxen by high-performance liquid chromatography and identification of its photoproducts by LC-ESI MS. Biomed. Chromatogr., 20, 787-793.

7. Sun Y., Zhang Z., Xi Z., Shi Z. (2009) Determination of naproxen in human urine by highperformance liquid chromatography with direct electrogenerated chemiluminescence detection. Talanta, 79, 676-680.

8. Shubhangi M. P., Bharat S. P., Chaudhari R. Y. (2010) Validated HPTLC Method for Simultaneous Quantitation of Domperidone Maleate and Naproxen Sodium in Bulk Drug and Formulation. Eurasian J. Anal. Chem.,13, 267-271.

9. Aresta A., Carbonara T., Palmisano F., Zambonin C.G. (2006) Profiling urinary metabolites of naproxen by liquid chromatography-electrospray mass spectrometry. J. Pharm. Biomed. Anal., 41, 1312. 
10. Gallo P., Fabbrocino S., Vinci F., Fiori M., Danese V., Serpe L. (2008) Confirmatory identification of sixteen non-steroidal anti-inflammatory drug residues in raw milk by liquid chromatography coupled with ion trap mass spectrometry. Rapid Commun. Mass Spectrom., 22, 841-854.

11. Phillips T.M., Wellner E.F. (2006) Measurement of naproxen in human plasma by chip-based immunoaffinity capillary electrophoresis. Biomed. Chromatogr., 20, 662-667.

12. Lu H.J., Ruan Z.Q., Kang J.W., Ou Q.Y. (2001) Simultaneous chiral separation and determination of the optical purity of naproxen and methyl naproxen by capillary electrophoresis with dual-cyclodextrin system as chiral selector. Anal. Lett., 34, 1657-1668.

13. Ibanez G.A., Escandar G.M. (2005) Combined liquid and solid-surface room temperature fluorimetric determination of naproxen and salicylate in serum. J. Pharm. Biomed. Anal., 37, 149-155.

14. Cheng X., Zhao L., Liu M., Lin JM. (2006) In vitro monitoring of nanogram levels of naproxen in human urine using flow injection chemiluminescence. Anal. Chim. Acta., 558, 296-301.

15. Li Y., Lu J. (2006) Flow injection chemiluminescence determination of naproxen based on $\mathrm{KMnO}_{4}-\mathrm{Na}_{2} \mathrm{SO}_{3}$ reaction in neutral aqueous medium. Anal. Chim. Acta., 577, 107-110.

16. Du J., Li D., Lu J. (2010) Chemiluminescence determination of naproxen based on europium (III)-sensitized KIO4-H2O2 reaction. Lumines, 25, 76-80.

17. Adhoum N., Monser L., Toumi M., Boujlel K. (2003) Determination of naproxen in pharmaceuticals by differential pulse voltammetry at a platinum electrode. Anal. Chim. Acta., 495, 69-75.

18. Suryanarayanan V., Zhang Y., Yoshihara S., Shirakashi T. (2005) Voltammetric assay of naproxen in pharmaceutical formulations using boron dopped diamond electrode. Electroanalysis, 17, 925-932.

19. Aresta A., Palmisano F., Zambonin C.G. (2005) Determination of naproxen in human urine by solid-phase microextraction coupled to liquid chromatography. J. Pharm. Biomed. Anal., 39, 643-647.

20. Gondalia R. P., Dharams A. P. (2010) Spectrophotometric simultaneous estimation of naproxen sodium and sumatriptan succinate in tablet dosage forms. Int. J. Pharmaceut. Biomed. Sci., 1, 2426.

21. Vinay W., Pendota S., Manjunth S. Y. (2011) Validated spectroscopic method for estimation of naproxen from tablet formulation. J. pharm. Res., 4, 2633-2635.

22. Trinath M., Saurabh K. B, Hari Hara T. D, Bonde C. G. (2010) Development and validation of spectrophotometric method for simultaneous estimation of Sumatriptan and Naproxen sodium in tablet dosage form. Der. Pharmacia. Sinica., 1, 36-41.

23. Amin A. S., Dessouki H. A., Moustafa M. M., Ghoname M. S. (2009a) Spectrophotometric methods for the determination of sertraline hydrochloride and clidinium bromide in bulk and in pharmaceutical preparations. Chemical Papers, 63, 716-722.

24. Amin A. S., Moustafa M. E., El-Dosoky R. M. (2009c) Utilization of colorimetric determination of sildenafil citrate (Viagra) through ion-associate complex formation. J. AOAC. Int., 92, 125130.

25. Amin A. S., Moustafa M., El-Dosoky R. (2008) Spectrophotometric determination of some fluoroquinolone derivatives in dosage forms and biological fluids using ion-pair complex formation. Anal. Lett., 41, 837-852.

26. Gouda A. A., El-Sheikh R., Zeineb E., Nagda H., Rham E. (2008) Spectrophotometric determination of hyoscine butylbromide and famciclovir in pure form and in pharmaceutical formulations. Spectrochimica Acta Part A: Molecular and Biomolecular Spectroscopy. 70, 785792. 